\title{
Nuevo florilegio de la poesía alemana en versiones peruanas
}

\author{
(Recopilación de Estuardo Núñez) \\ de Johann Wolfgang von Goethe
}

\section{A M U E R T E}

(Goethe)

La imagen de la muerte no se presenta al hombre sabio como un objeto de espanto, $\mathrm{ni}$ al hombre piadoso como un término último; ella incita al primero al estudio de la vida y le enseña a aprovecharse de ella y presenta al segundo un porvenir de felicidad, y le dá la esperanza en medio de los días de tristeza. Tanto para el uno como para el otro la muerte llega a ser la vida. Es necesario ofrecer al joven, el cuadro de una noble ancianidad y al anciano el de la juventud, para que ambos se complazcan en ver este círculo eterno y que la vida termina en la vida.

(Versión anónima publicada en "El Instructor Peruano", No 1o, p. I, Lima, 1847).

\section{EL.ARROY U ELO \\ Blbliotecade Letras (Gothe)}

\section{Mientras plafeado manso arroyuelo}

pasas y nunca vuelves atrás;

en tus orillas dice mi anhelo:

¿de dónde vienes? ¿adónde vas?

Vengo del seno de obscuro abismo, por musgo y flores vó mi raudal, tan transparente, que el cielo mismo busca su imagen en mi cristal.

Por eso miras mi faz risueña; ruedo empujado, no sé por quien; mas quien me trajo de ruda peña ese mi guía seró también.

(Versión de Juan de Arona, publicada en "El Chispazo" No 15, p. I, Lima, 23 de enero de 1892). 


\section{LIEDER ALEMANES}

\section{A D I Ó S}

Deja, deja, bien mío,

Tú la que adoro, tú mi único amor

Ay! que mis ojos, ya que nó mis labios,

Te den en una lágrima su adiós!

Al partir de tú lado

Siento que se me muere el corazón;

Yo tengo fuerza varonil, soy hombre,

Mas, ¿podré resistir tanto dolor?

Mira, en este momento

Todo es triste, sombrío, infunde horror,

Tus besos son sin fuego, y ya no tiene

Ni fuerza de tu mano el apretón.

En tiempo más dichosos,

Una caricia hurtada a tu pasión

¡Cómo inundaba de placer el alma!

Cuớn venturoso me creía yo!

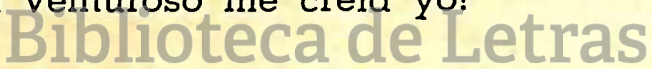

Así nos extasiamos

Al contemplar con infantil candor,

A la humilde violeta que la brisa

De mayo en las mañanas perfumó.

Pero ahora, mi mano

Los ramilletes que otra vez formó

Ya no te formará, ni irá una rosa

A colocar sobre tu corazón.

¿Ves, querida Francisca?

Para el que te ama, primavera es hoy;

Mas ¡ay! que es triste otoño para esta alma

quel nació $\mathrm{y}$ vive $\mathrm{y}$ muere en el dolor!

(Versión de Modesto Molina; véase nota del poema siguiente). 


\section{LEJOS DE ELLA}

(Goethe)

Yo en tí pienso,

Cuando el sol los vivos resplandores

Reflejan y se esparcen sobre el mar;

Yo en tí pienso,

Cuando la luz tranquila de la luna

Se mira en la corriente rielar.

Yo te veo,

Cuando á lo lejos, y sobre el camino

Polvareda alza el viento al resbalar;

Yo te veo,

Cuando el viajero en una senda estrecha,

Tiembla de la nocturna obscuridad.

Tu voz oigo,

Si con un ruido sordo, allá a lo lejos,

Braman las olas del inquieto mar;

Tu voz oigo,

Cuando está el bosque triste y solitario;

¡En el silencio siempre te oigo hablar!

Voy contigo,

Y á tu lado, ya cerca ó muy distante;

A donde estés estoy, siempre detrós,

Voy contigo,

Tu sombra soy y la mitad de tu alma, !Eres tú de mi ser la otra mitad!

$\mathrm{Si}$ te viera

En este instante que la noche asoma

$Y$ miro las estrellas titilar!

Si te viera

En este instante que á alumbrarme vienen!

¡Oh, si estuvieras tú, mi bien, allá!

(Versión de Modesto MOLINA, fechada en Yquique, agosto de 1874 , y publicada en "El Correo del Perú", Lima, I 3 de setiembre de 1874 , No 37 , año IV). 


\title{
H A N S E L
}

(Gocthe)

\begin{abstract}
En la montaña sentéme $Y$ me puse a contemplar los pájaros que cantaban de la aurora al despertar, haciendo sus nidos acá y acullá.
\end{abstract}

Después las abejas viendo me detuve ante un jardín; que construían colmenas y revoloteaban ví corriendo, ligeras de aquí para allí.

Pasé después por el prado Biy un juegoen él contemplé de mariposas libando de las flores jugo y miel.

Su gracia y vaivenes qué bellos hallé!

Pero Hansel se me presenta le hago esa ventura ver, y después, los dos alegres, lo propio hacemos después, $y$ es su alma mi alma,

$y \mathrm{mi}$ fe su fe.

(Versión de Modesto MOLINA, publicada en "El Correo del Perú", Lima, 13 de setiembre de 1874, año IV). 
De Fricdrich won Schiller

\section{HIMNO AL PLACER}

Freude, schöner Göttersunken,

Tochter aus Elysium

Wir betreten feuertrunken

Himmlische, dein Heiligtum.

Schiller, "An die Freude".

I

Hijo hermoso del grande Eliseo.

Que en el trono de Dios centellea,

deja al cielo que tanto recrea

la luz pura de tu alma fulgor.

¡Oh placer! a la tierra ilumina;

haz que el hombre, del hombre sea hermano;

bajo tu ala cobija al humano

que ya acata la ley del Señor.

$\sim$ Coro

Un abrazo millones de seres;

$y$ dejad que en el orbe también

suene el besolde paz y placeres. tras

en memoria del Dios del Edén.

\section{II}

El que goza de un bien de fortuna

siempre encuentra un amigo do quiera;

$y$ al que tenga feliz compañera

no la dicha vengais a turbar;

todo aquel que la tierra transite

el amor alimente en el alma,

y que al llanto no turbe la calma

de su dulce y tranquilo soñar.

Coro

A la noble, ieliz simpatía homenaje rendidle, mortal; 
ella muestra la patria del día donde mora ese Rey celestial.

\section{III}

El placer nos ofrece su copa Apuradla mortal, con dulzura, y al abrazo de paz de natura beba el bueno y el ruín pecador. El nos brinda su beso amoroso; fiel amigo, al morir, nos enseña del Querube la imagen risueña, bajo el trono del gran Hacedor.

\section{Coro}

No bajéis a la tierra mortales, anticípate, mundo, en buscar a la luz de estrellados fanales, el placer que allí debe morar.

\section{Biblioteca de Letras "Jorge Puccinelli Converso"}

A la eterna y festiva natura la nombramos placer y consuelo; $y$ es placer el que muestra en su vuelo de la esfera el grandioso reló; a su soplo la flor abre el cáliz, sale el sol a brillar refulgente; rueda el orbe con calma imponente tras mil astros que el hombre no vió.

\section{Coro}

Gira siempre alrededor de la gloria con el astro que alumbra al Edén cual guerrero que va a la victoria id, hermanos, en pos de él también. 
La verdad misteriosa refleja; al que busca su encanto acaricia, y conduce al mortal con delicia a la cima do mora la fe.

$\mathrm{Su}$ bandera miremos ondeante de la muerte en el golfo profundo; contemplemos su luz de otro mundo del angélico coro en el pié.

Coro

Soportad, joh millones de seres! este mundo por otro mejor; en la esfera estrellada hay placeres que nos brinda amoroso el Señor.

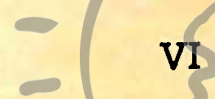

El que es bueno en la tierra no busca recompensa ni lauro esplendente, la aflicción y miseria doliente buscan sólo el pldcer seductor. La venganza a su nombre se olvide, y sea el hombre, del hombre un amigo, 0 " y el más cruel y alevoso enemigo lance fiero del pecho el rencor.

\section{Coro}

La palabra delito borremos ya del libro del triste mortal; $\mathrm{y}$ al humano benignos juzguemos, cual nos juzga ese Dios eternal.

\section{VII}

El placer, ya destila en su copa la purpúrea y clarísima esencia, $y$ ella infunde coraje y clemencia 
al guerrero a quien falta el valor.

Id, hermanos, bebed; el asiento por un rato tan sólo dejemos, y la espuma que arroja veremos transformarse en aéreo vapor.

\section{Coro}

Esa esencia tan grata y divina ya la apura algún ser celestial; las estrellas con voz peregrina hoy le elevan un himno inmortal.

\section{VIII}

Socorramos la pura inocencia que lamenta su falta de abrigo: $y$ al amigo y al cruel enemigo la verdad enseñemos también: destruyamos la imupra mentira; la verdad coronad, reverente; y mostrad ante el trono, ferviente el respeto del hombre de bien.

\section{Bibliotecacoro Letras}

\section{"Jorge Puccinelli Converso"}

Y juremos la paz y la alianza acatando la ley del Señor; tras el éter está la esperanza, $\mathrm{y}$ una vida de goce $\mathrm{y}$ amor.

Versión de $\boldsymbol{E}$. de Ricof (ó Dalmiro) - Federico Flores Galindo - publicada en "El Correo del Perú", No. XI, año I, (Lima, 25 de noviembre de $187 x$ ).

\section{EL REPARTO DE LA TIERRA}

(De "Die Teilung der Erde" de Schiller).

- Tomar el mundo! - Zeus desde su altura

Dijo al hombre : ique escoja cada cual! 
Feudo vuestro será toda su anchura :

Partido con cariño fraternal!

Y acá, mezclando las rapaces manos,

el joven y el decrépito llegó :

El labrador se adjudicó los llanos,

$y$ el hidalgo los bosques escogió.

El mercader colmó trajes ingentes;

Ranciados vinos trasegó el abad;

Veda el rey los caminos y los puentes

Y exclama : "iSea el diezmo mi heredad!".

Después de repartido el mundo todo,

Desde lejos, el vate soñador

Llegó; más de dotarle no hubo modo;

Ya tuvo toda cosa su señor.

- ¡Ay triste! sólo a mí me has olvidado.

A mí, de entre tus hijos el más fiel!-

Así exclamó, y tiróse anonadado

De Jove en el riquísimo escabel.

¡Tú, perdido en el reino de los sueños,

¿Por qué - el Dios dijo - no estuviste aquí

Cuando notába a grandes y pequeños

-Yo estaba - dijo el vate - junto a tí.

Extasiaron mis ojos tus fulgores

Mis oídos los cantos de tu edén....

Perdona al que bebiendo tus amores

Sabe olvidar el deleznable bien.

—¿Qué hacer - repuso el Dios - si ya está hecho?

Frutos y caza y mercancías dí

¿Quieres vivir conmigo en lazo estrecho?

Pues ven, y abriré el cielo para tí! 


\section{I C O R A Z O N}

De Heinrich Heine

Du schönes Fischermaedchen, Heine

Hermosa pescadora, gobierna tu barquilla

$y$ a tierra sin demora

ven, que te aguardo en la desierta orilla.

A mi lado reposa

$\mathrm{y}, \sin$ recelo alguno $\mathrm{y}$ sin cuidado,

sobre mi corazón tus sienes posa,

cual te confías sola al mar airado.

Mi corazón que al mar es semejante,

flujo, y reflujo y tempestades tiene;

mas, como él, jcuánta perla fulgurante,

en su bronce contiene!.......

(Traducción de Adriana - Adriana Buendia-, Lima, 1873, publicada en "El Correo del Perú", No. 17, Lima, 26 de Abril de 1873).

\section{$S$ U I M A G E N}

\section{Biblioteca wenn ich auf dem Lager liege, Heine}

\section{"Jo Cuando tiendellilenciosarso"}

la noche su manto negro,

una dulcísima imagen

se cierne sobre mi lecho.

$Y$ apenas mis tristes ojos

se cierran al blando sueño,

misteriosa se desliza

en medio de mis ensueños.

Mas no huye como las sombras,

cuando el sol brilla en el cielo, que todo el día, conmigo,

la llevo dentro mi pecho.

(Versión de Adriana, Adriana Buendia, Lima, 1873, publicáda en "El Correo del Perú"; No I5; 12 de abril de 1873 ). 


\section{R U I D Q Q U E E S P A T A}

(Imitación de Heine).

Ven y reclina tu seren $\alpha$ frente en $\mathrm{mi}$ angustiado pecho, Y díme si oyes los terribles golpes que en él se dan, con horroroso estruendo.

Son los que da con su feroz martillo un cruel carpintero. que sin cesar de día ni de noche, en él trabaja mi ataud funesto........

Escuchaste? pues bien, al punto ordena que su obra acabe, por piedad, el maestro, que ese ruído fatal que me acongoja, ha mucho tiempo que me quita el sueño.

- (Imitación de Adriana, -Adriana Buendía, escritora arequipeña - Lima, 1873, publicada en "El Correo del Perú", No 16, ig de abril de I873).

Biblioteca de Letras "Jorge Puccinelli Converso"

I

TU IMAGEN

(H. Heine)

Yo no temo el fragor de la catástrofe ni del dolor la funeral tortura, si en mi conciencia se refleja hermosa tu imagen pura,

Cuando el abismo me devore impío y nos separe eternidad oscura, en mi memoria llevaré triunfante tu imagen pura. 
Y si aquel sueño de futura gloria

es vanidad y mundanal locura, en cada uno de mis tristes átomos subsistirá ¡mujer! tu imagen pura......

\section{II}

\section{PASION E TER N A}

Yo te he jurado una pasión eterna porque eres tú mi refulgente sol, porque en las sombras de mis tristes dudas ¿Qué sería sin tí mi corazón?

De la existencia en la áspera montaña que se eleva entre océanos de dolor $y$ en cuya cumbre el desengaño impera, ¿Qué sería sin tí mi corazón?

Si ambiciono laureles y coronas, si quiero nombre, fama y esplendor, si combato y persigo en las tinieblas, es porque alumbras tú mi corazón. Blolioteca de Letras

Sin th́ qué importa la yirtud, la gloria, abismo ó cielo, Satanás o Dios. seguir la ciencia o la ignorancia ruda, tener o no tener un corazón!....

(Versiones de Arturo Morales Toledo, publicadas en "El correo del Perú"; año IV, No XXX, Lima, Julio de 1873).

\section{I E D E R}

(De "El Libro de Lázaro", de H. Heine)

\section{I}

Eres rubia y graciosa

y tan bella y radiante como fría,

en vano mi alma ansiosa 
esperaba el momento de alegría en que, extinguida de tu pecho el pasmo, brotase llamaradas de entusiasmo!

De entusiasmo sublime

por toda acción magnífica y grandiosa que el humano redime,

de entusiasmo que el vulgo de la prosa menosprecia en su vil materialismo, única luz en este horrible abismo.

En aquel tiempo, durante los días de verano encantadores, íbamos del Rhin ondeante a su orilla de viñas $y$ de flores, do los rayos de Ápolo sonreían y las auras perfumes despedían.

Sus besos nos enviaban los claveles de púrpura que cual llamas quemaban, y yo en las margaritas humildosas en mis ensueños desplegarse vía una vida adeal del poesia!li Converso"

$Y$ tú ibas a mi lado con tu traje de raso blanquecino como el ángel deseado, con dulce calma y esplendor divino, cual las castas doncellas que elocuente Netscher nos traza con pincel valiente.

Pero entonces en medio

de ese espléndido cuadro de natura, con matador asedio me perseguía funeral tristura, porque tan sólo un corazón de nieve se hallaba oculto en tu ropaje leve! 
II

Absuelta libremente

en el supremo Tribunal has sido

de la razón Potente!

Así el fállo se encuentra concebido:

$\mathrm{Ni}$ con palabras ni hechos ha violado

las promesas que un dia hubo jurado!

Allí muda, indiferente

te hallabas tú, mientras furiosas llamas

incendiaban $\mathrm{mi}$ mente,

tú no atizabas de mi amor las flamas, mas, sin embargo, y con ignota pena mi corazón airado te condena!

En mi agitado sueño

se levanta una voz acusadora

con enérgico empeño,

que se querella de tu acción traidora

y sostiene tras fúnebre gemido,

que esta acción para siempre me ha perdido.

$\mathrm{Y}$ sus pruebas aduce, Letras

y presenta testigos imatadores,

$\mathrm{y}$ conmueve $\mathrm{y}$ seduce,

mas del día, a los prístinos albores, se borran como sombras en el viento

sueño agitado, acusador acentol

Pero al fondo de mi alma

se refugian con su hórrido proceso,

y huída ya la calma

$y$ del dolor en el fatal exceso, sólo queda un recuerdo maldecido:

¡Qué ese amor para siempre me ha perdido!

III

Tu carta joh virgen fría!

ha sido cual relómpago que hiende 
la inmensidad sombria

y que la noche de un abismo enciende:

Yo he visto a los destellos que fulgura

¡cuán profunda es mi horrible desventura!

Tú al fin, al fin te sientes

por $\mathrm{mi}$ infortunio a compasión movida

y das ayes dolientes;

tú, tú que en el desierto de mi vida

te alzabas como estatua regia y muda

bella cual mármol, cual granito ruda!

¡Oh Dios, Dios poderoso!

¡̇i seré, si seré yo desgraciado!

Ella con labio ansioso

y con acento de pasión me ha hablado!

Lágrimas ella de sus ojos vierte!

¡Hasta el mármol se apiada de mi suerte!

Lo que yo he visto en Ella

mi lóbrega existencia ha desquiciado!

¡Oh Providencia bella

envíame el descanso suspirado,

de la vida en la senda aborrecible

da pronto fin a mi tragedia horrible!

"Jorge Puccinell Converso"

(Versioncs de Arturo Morales Toledo, publicadas en "El Correo del Perú", NQ V, año VII, febrero de 1877 ).

\section{LOS DOS GRANADEROS}

(Romance de Eurique Heine, escrito en 1816)

Camino de Francia van

dos soldados de la guardia

que prisioneros en Rusia

ha largo tiempo que estaban.

Cuando llegaron ansiosos

a los campos de Alemania 
inclinaron su cabeza

con profunda pena amarga.

Allí supieron los bravos

que se había hundido Francia,

que el grande y glorioso Ejército

destrozado se encontraba

y que él, El Emperador,

el César de eterna fama

agonizaba cautivo

de la potencia britónica;

a tan lamentable nueva

los valientes de la Guardia

como dos sensibles niños

vierten dolorosas lágrimas.

Dijo el uno:- "iCuánto sufro!"

"Mis heridas se dilatan"

y por sus fauces abiertas

al fin mi vida se escapa!"

Y dijo el otro: Ha acabado!"

"toda ambición y esperanza!"

"También yo morir quisiera;

¡Es horrible mi desgracia!"

"Pero allá en mi aldea tengo

hijos y mujer amada Letras

que sin mí perecerían

de hambre en su pobre comarca.

Mas qué importan mujer e hijos si otras cuitas sufre mi alma". '¡Mendiguen si tienen hambre!"

"Napoleón lejos de Francia prisionero en una roca el Señor de las batallas!"

- Atiende, atiende mi ruego, antiguo y leal camarada:

Si muero aquí, ve y sepúltame, en la tierra de mi patria. pon en mi pecho la Cruz de Honor con cinta encarnada, ponme el fusil en la mano como en tiempo de campaña y también cuélgame al cinto 
la firme y gloriosa espada; quiero estar en mi sepulcro cual vigilante fontasma $y$ aguardar a que retumbe la estruendorosa metralla y a que resuene el galope de caballería rápida, $y$ el Emperador entonces montado en su altivo Acacia al ruído de los tambores pisará mi tumba helada y yo saldré de mi tumba armado $y$ con fiera planta para defender en medio de la militar borrasca al ungido de la gloria al Emperador de mi alma!"......

(Versión de Arturo Morales Toledo, publicada en "El correo del Perú", añoVII, No VII, Lima, febrero de 1877 ).

\section{BÄLADDACIEMANAS "Jorge Puccinelli Conyer. Heine)}

La noche se extendió sobre mis ojos, tenía plomo dentro la boca muda, e, inerte el corazón y la cabeza, yacía en lo más hondo de la tumba.

Después de haber dormido no sé cuónto al despertar de mi profundo sueño, me pareció escuchar una voz dulce que llamaba a mi triste oscuro lecho.

- ¿Dime Enrique, por qué no te levantas? el día eterno en los espacios brilla, los muertos han dejado sus sepulcros y la inmortal ventura ya principia. 
-Amor mío, no puedo levantarme, pues yazgo ciego en mi sombrío fondo, a fuerza de llorar se han apagado Ay! para siempre mis enjutos ojos.

-Ija noche que los cubre con sus alas voy a quitar, Enrique, con mis besos es menester que mires a los ángeles y el esplendor divino de los cielos.

¡Amor mío, no puedo levantarme, porque la acerba, dolorosa herida que abrió en mi pecho una palabra tuya, siento que sangre sin cesar destila.

-Voy a poner, Enrique, dulcemente, sobre tu herido corazón mi mano; no brotará tu sangre generosa y quedarás de tu dolencia salvo.

¡Mi amor, no puedo levantarme, tengo otra herida cruel en la cabeza; cuando me fuiste arrebatada, el plomo mi cráneo penetró con bala fiera. aS

- Voy a cerrar, Enrique, con las trenzas de mis cabellos tu mortal herida; con ellas contendré toda tu sangre y la cabeza moverás altiva.

Era la voz tan dulce y melodiosa, que, no pudiendo resistir su magia, alzarme quise de mi horrenda córcel y rápido correr donde mi amada.

Mas, de pronto se abrieron mis heridas, brotó de mi cabeza y de mi pecho con violencia, un raudal de hirviente sangre, Y..... idesperté de mi agitado sueño!

(Traducción de Manuel Rafael Valdivia, insertada en Lira Arequip'eña, Arequipa, Imp. de Manuel Pío Chaves - 1889). 


\section{A S ONDINA S}

(De Heinrich HEINE)

Besan las ondas la desierta playa, brilla en el cielo la plateada luna, $y$ un doncel, en la arena reclinado, sueña en horas de amor y de ventura.

Entre leves espumas, las ondinas, salen del mar, fantásticas y puras, y llegóndose al joven, cautelosas, hablándose entre sí "duerme" murmurơn.

Una - mujer al fin - curiosa toca de su cimera la fluctuante pluma, otra levanta el rutilante escudo y presto el mote descifrar procura.

Esta risueña y de mirar de fuego la limpia espada del doncel desnuda, $\mathrm{y}$ apoyándose en ella lo contempla con éxtasis de amor y de ternura.

Aquella en tormo de él gira amorosa, y hablando con pasión, tiema susurra; ¡Cuán bello estás así, flor de la guerra; !Cuánto diera por ser amada tuya....

Una aprieta su mano y se la besa; cobrando ánimo la otra, blanca y rubia, bermejas las mejillas, a sus labios los labios del doncel con pasión junta.

No duerme el caballero, siente todo...... pero el sueño su aspecto lo simula, y se deja besar por las ondinas al suave rayo de la blanca luna!

(Versión castellana de Diego Masias y Calle, inserta en Lira Arequipeña, Arequipa, Imp. de Manuel Pío Chaves, 1889). 


\section{G $A$ C E L $A$}

Mein Liebchen, was willst Du mehr?

II. HEINE, Die Hcimkchr.

Tienes rosas en los labios..... ¿más deseas, oh mujer?

Tienes lirios en los ojos...... ¿más deseas, oh Mujer?

Tienes gracia $\mathrm{y}$ hermosura, juventud $\mathrm{y}$ admiradores,

Tienes joyas, tienes galas...... ¿más deseas, oh Mujer?

A los lirios de tus ojos y a las rosas de tus labios

Alzo nubes de canciones...... ¿más deseas, oh Mujer?

Soy el eco de tus labios, la falena de tus ojos;

Soy la sombra de tu sombra.... ¿más deseas, oh Mujer?

En tu voz $y$ en tu mirada tengo dichas y martirios,

A tus plantas vivo y muero...... ¿más deseas, oh Mujer?

(Versión de Manuel González Prada, inserta en Exóticas, Tip. El Lucero, Lima, IgrI).

\section{OTROS ROMANTICOS}

\section{LA MUJER DEL PESCADOR Bibliotecabalada de ematthias claudius (1740-1815) "Jorge Puccinelli Converso»}

En una pequeña choza

De paja y tablas construída

Vive Aldén el pescador

Con su esposa muy querida.

Allí a la orilla del mar Amóndose con pureza, Los dos esposos vivían Felices con su pobreza.

Un día, muy de mañana,

Se marcha a la pesca Aldén,

Estaba la mar azul,

Azul el cielo también. 
Echa la red en el agua,

Deja un poco que el tiempo ande

$\mathrm{Y}$ al retirarla ve en ella

un pez muy grande, muy grande.

Pero el pez que no era pez

Sino un príncipe encantado,

Le dice de esta manera

A Aldén que le oye espantado:

"No me lleves a morir

Y si me dejas la vida,

Yo te daré pescador

Cuanto el deseo te pida".

Aldén lo suelta y se vuelve

$Y$ cuenta el lance a su esposa,

Ella le escucha en silencio

$\mathrm{Y}$ luego dice ambiciosa :

"Verdad que somos felices

Viviendo aquí con amor,

Pero lo fuéramos más

En una chozg mejor". de Letras

"Andd. esposo ix pideal peznverso"

si eso dél es verdad,

Que nos dé una choza grande

Que tenga comodidad".

Aldén sumiso y amante toma otra vez el camino, El mar está siempre en calma pero no tơn cristalino.

Al pez llama y el pez sale, Aldén lo ve con placer,

$Y$ le dice humildemente

Lo que pide su mujer.

"Pescador vuelve a tu casa, Que ya mi poder la eleva", 
$Y$ en efecto el pescador

Encuentra una choza nueva.

Tiene más habitaciones, Cocina, leña encendida, Buena mesa, buena cama $\mathrm{Y}$ despensa bien surtida.

Su mujer con buena ropa Sus hijos abrigados, Todos locos de alegría En el hogar agrupados.

Después de unos cuantos días

Dice la mujer "Jamás,

Me contentaré con esto,

Pudiendo ser mucho más.

Para mi dicha completa

$\mathrm{Me}$ falta una cosa ahora

$\mathrm{Ve}$, Aldén yl pídele di pez

Que me haga una gran señora".

Aldén exhala un suspiro $Y$ marcha no muy resuelto Esta vez estaba el mar Medio verdoso y revuelto.

Al pez llama y el pez sale Aldén le ve con placer $Y$ le dice algo turbado Lo que quiere su mujer.

"Pescador vuelve a tu casa Ya está lo que has pedido" $Y$ el pescador al volver Halla un lujo demasiado. 
Su mujer está vestida con elegante insolencia Y a las más altas señoras Humilla con su opulencia.

Tiene joyas y carruajes Recibe nobles visitas, $\mathrm{Y}$ da bailes esplendentes $Y$ comidas exquisitas.

\section{III}

Una noche al pescador Dice la esposa querida, Aldén yo quiero algo más porque me cansa esta vida.

"Ve Aldén y díle $\alpha$ tu pez que sobre un trono me siente. con manto real en mis hombros $\mathrm{Y}$ una corona en mi frente".

El pescador amoroso, Camina llorarido a solas El mar estaba rojizo

y encrespándose las blăs. onverso"

Al pez llama y el pez sale, Ya Aldén no siente placer, $Y$ le dice muy confuso

Lo que pide su mujer.

"Pescador, ve a tu palacio;

Ya reina tu esposa es".

Y Aldén encuentra a su esposa con una corte a sus pies.

Es la excelsa soberana, Sus miradas son favores, Todo un pueblo la saluda, La sirven grandes señores. 
La ciudad está de gala

Se oye entusiastas cantares, $\mathrm{Y}$ hurras $\mathrm{Y}$ vivas alegres

$\mathrm{Y}$ músicas militares.

$Y$ entre fiestas $y$ paseos, Lisonjas y cortesías, Con su paso inexorable Siguen andando los días.

\section{IV}

Una ocasión la mujer Le dice : No soy dichosa; Creí que el trono era todo Pero el trono es poca cosa.

Me canso de tanto halago Que ya no me hace gozar, Me cansa el lujo y me canso de dar mi mano a besar.

"Qué más pedir?, dice Aldén, de nuestras almas ingratas, etras El pez puede fastidiarse si se fastidia, lo matas.

"Ve, Aldén, y díle a tu pez que no encuentro saciedad, Que si su poder es tanto Me dé la felicidad.

Cabizbajo sale Aldén, con el alma desgarrada, Esta vez el mar estaba en tempestad desatada.

Al pez llama y el pez sale, $Y$ viéndolo aparecer, Aldén le dice temblando Lo que pide su mujer. 
Pescador vuelve a tu casa, Aldén vuelve con presteza, Y halla...... su antigua cabaña con su paja y su pobreza.

Sus hijos medio desnudos,

Su mujer en el refugio,

Pero todos muy alegres comiendo el pan del trabajo.

Toma su red y contento

Se vuelve a la pesca Aldén, Ya la mar estaba azul, Y azul el cielo también.

\section{ADAN Y EL QUERUBE DEL PARAISO}

(Versión de Oswaldo B. Pflücker, publicada en "Boletín Eclesiástico", Trujillo, Diciembre de 1944).

De Friedrich Adolf Krummacher (1767-1845)

Cuando Abel yacía en su sangre y cerca de la víctima lloraba Adán, dirigióse el querube del Paraíso al padre del linaje humano, se colocó silenciosamente junto a él y su frente era grave; Adán levantó la vista y dijo : ¿Esta es una imagen de la generación a que he de dar orígen y así será vertida de nuevo, en lo futuro, la sangre fratemal por mano de los hermanos, manchando la tierra?

El querube respondió : Tú lo dices.

¡Ay! ¿Cuál seró el nombre que designe este horrososo hecho? preguntó Adón.

Con una lágrima en los ojos, respondió el celeste ser :

¡Guerra!

Tembló entonces el padre del género humano, suspiró y dijo : ¡Ay! ¿por qué, pues, debía caer el noble y justo bajo la mano del injusto?

Calló el querube.

Pero Adón continúo en sus quejas, añadiendo :

¿Y ahora qué me queda en mis miserias, sobre la tierra man. chada de sangre? 
El querube respondió :

"Dirigir tu mirada al cielo".

Empero Adán se quedó allí hasta la puesta del sol y cuando brotaron las estrellas, alzó sus brazos tendiéndolos a Orión y la Osa y exclamó :

.. ¡Oh vosotros, centinelas brillontes en las puertas de los cielos! ¿Por qué camináis tan silenciosas? Si es permitido a un mortal oír el eco de vuestras voces, habladme entonces del mundo de más allá, y del amado Abel.

En aquel instante aún había más silencio en derredor y Adán cayó sobre su rostro, orando.

Y escuchó en su corazón una apagada voz que le decía : Mira, Abel tu hijo vive.

Entonces, con esto, se alejó consolado y su alma quedó quieta y llena de tristeza.

(Traducción de Manuel María Romero, publicada en "El Correo del Perú", No. IV, año V, enero de 1875 ).

\section{EL EPITAFIO DE LA JOVEN}

\section{Biblioteca de (Balada aremana de J. L. Rueneluery)}

Con las manos coloradas, después de ver a su amante, viene una cóndida joven, y le pregunta su madre: - ¿Por qué, hija mía, tus manos hoy tan coloradas traes?

- Por que al coger una rosa, sacóme una espina sangre.

De nuevo vuelve la niña de otra cita con su amante $y$ al ver sus labios tan rojos temblando dijo su madre :

- ¿Por qué, hija mía, tus labios hoy tan encendidos traes? -Comí moras y su jugo me los tiñó de granate. 
Otra vez viene la niña después de ver a su amante; tiene el rostro melancólico $y$ le pregunta su madre : - ¿Por qué revela, hija mía, tanto dolor tu semblante?

-Madre! haz abrir una hueza $y$ que dentro de ella me guarden pónme und cruz en el pecho y haz que sobre esa cruz graben un epitafio en que lea quien por mi sepulcro pase : - "Un día trajo las manos como si vertiera sangre, porque estrechóndolas hubo entre las suyas su amante : Otra vez trajo los labios, rojos como dos corales, porque con besos de fuego se los encendió su amante : Una noche, en fin llegó pálida como un cadáver..... a la tumba la condujo la ingratiud de su amonte"d L Letras

"Jorge Pucci(versión española de (Manuel Rafael Valdivia, inserta en Lira Arequipeña, colección de las más selectas poesías de los vates antiguos y modernos. - Arequipa, Imp. de Manuel Pío Chaves, I889, 647 Pp.).

\section{EL EPITAFIO DE UNA JOVEN}

(de Johann Ludwig RUENEBERG, finlandés I804-1 877).

De ver a su amante, sola vuelve la niña a su hogar; sus manos, antes de azahar, trae rojas cual la amapola. 
- ¿Porqué a ese color te inclinas?,

La madre le dijo así.

- Cogiendo rosas me herí con las punzantes espinas.

En su casc: otra mañana entró alegre y sin enojos. Pero con los labios rojos como el color de la grana.

- ¿Por qué ese color advierto en tu boca diminuta?

- Bs el jugo de la fruta que me he comido en el huerto.

Otra vez cruzó la puerta de su hogar triste y llorosa;

Mas sus mejillas de rosa, eran ya las de una muerta.

Y su madre aquella vez al mirarla tan sombria, así la dijo:- Hija mía qué indica tu palidez?

\section{"Jorge Puccinelli Converso"}

- Madre, exclamó la doncella con la mayor amargura: haz que abran mi sepultura $y$ que me acuesten en ella.

$Y$ que pongas también quiero, cuando me falte la luz, en mis manos una cruz $y$ en $\mathrm{mi}$ fosa este letrero:

Con las breves manos rojas un día a su hogar volvió; porque se las estrechó su amante entre mil congojas. 
Otra vez sus labios gruesos en tïntá roja teñía;

pues su amante los había cubierto de ardientes besos.

Y otra, con semblante huraño

a su triste hogar volvió, porque el amante pagó

su amor con un desengaño.

(Versión del mismo poema ahterior, por J. $\boldsymbol{M}$. $M$. publicada en "La Revista Social", Lima, 3 de abril de 1886).

\section{I P A TRIA}

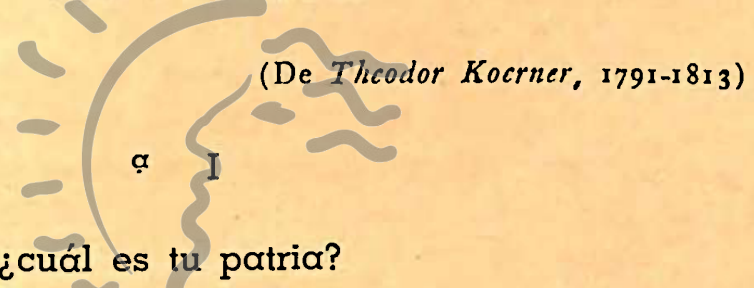

Cantor ¿cuál es tu patria?

-Aquella tierra

en que la inteligencia obtuvo palmas;

donde lo bello y lo que es grande y noble

lauros eternos y coronas hallan;

Donde" el tálento conquistóse premios,

Allí estuvo mi patria.

\section{a II}

- ¿Cuál es el nombre de tu Patria, bardo?

-La que hoy sobre sus hijos, desolada,

bajo extranjero cetro gime y llora;

ese país del honor es la Germania;

el suelo de los robles seculares,

se llamó así mi Patria.

a III

- ¿Y por qué llora tu nación, poeta?

-Porque tiemblan sus príncipes y bajan 
la frente ante el furor de los tiranos; porque ven rotas sus promesas santas, y porque nadie escucha sus clamores, llora triste mi Patria.

\section{a IV}

- ¿A quién dime cantor llama tu pueblo?

Con la tonante voz desesperada, a sus dioses, ahora enmudecidos, por su perdida libertad reclama llamando que la salven y la venguen; Eso pide mi Patria.

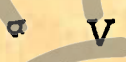

- ¿Y hoy qué ambiciona tu país, poeta? - Hundir a los serviles que la ultrajan; lanzar al amo cruel que entró en su seno; ver a sus hijos libres de la infamia o en la arena cavarles libre tumba, ¡Eso espera mi Patria!

\section{Bibliotecavile Letras}

\section{- ¿Y confía tu Patria en la victoria?}

-Espera en la justicia de su causa; En que pronto su pueblo se despierte, $y$, poniendo en el cielo su venganza, en que se acerque la hora de su triunfo. |Eso espera mi Patria!

(Versión de Modesto Molina, aparecida en "La Revista Social" No ro6, Lima, 28 de Julio de 1887 ).

\section{LA VENGANZA DE LAS FLORES}

(De Ferdinand FREILIGRATH)

Entre blandos cojines reposa y dormita una bella mujer, 
cuya luenga pestaña sedosa

como un fleco se ve descender.

Alba copa en la silla cercana embriagante derrama el olor de las flores, que en esa mañana ella misma cogió con amor.

La abrasada canícula impera y cerrados ventana y balcón, el mullido retrete exagera de la atmósfera el alta presión.

De improvisto el ambiente se agita y de cada corola en redor algo bulle, se mueve, palpita; cuchicheo se siente y rumor.

Y las flores, las fibras más tiernas, con latidos de vida $y$ placer se estremecen, y a formas externas se les ve poco a poco dar ser.

De fragancias $y$ esencias son almas que vestidas de niebla $y$ de tul, traen coronas, y escudos y palmas, $y$ en atmósfera flotan azul.

De una rosa desprende su planta una esbelta mujer ideal, su cabello el rocío abrillanta que del seno sacó maternal.

En pos de ella magnífico, atónito, caballero de audaz corazón, desde el casco se alzó del acónito, con espada y luciente morrión.

Una garza de pluma plateada dió a su casco el penacho que ves, 
y más lejos temblando una hada aún apoya en un lirio sus pies.

Con su verde turbante un Etíope de su cáliz brotó el tulipán. $y$ del verde turbante en el tope brilla de oro el airón musulmán.

Al monarca que rija esta corte la corona imperial cetro dió, $y$ el gladiolo la armada cohorte que le monte la guardia de honor.

Un mancebo de torva mirada de un narciso se eleva sutil, y su boca en la boca preciada va a estampar con anhelo febril.

$Y$ al lecho todos en tropel se acercan en danza circular, desordenada, y mientras con su anhélito la cercan, le cantan a la niña esta tonada:

"Tú nos sacaste de la madre tierra niña, y al duro sene nos trajiste tras do nuestro cáliz se marchita y cierra, y nuestra vida languidece triste.

No más soplo de auras placenteras rendiremos el tallo; ni en la noche jugaremos cual sílfides ligeras nacidas ¡ay! de nuestro verde broche.

No más aire ni luz! No más rocío, ni aguas que bañen nuestro pie al soslayo, ni árboles que abran el ramaje umbrío para que el sol nos pueda enviar su rayo!

Muramos pues en este vaso frío. trasmitiéndote a tí nuestro desmayo, y pues tú nos quitaste la existencia muere embriagada en nuestra propia esencia". 
Cesa el canto y se inclinan anhelantes insuflando a la niña su vapor, vuelve el silencio fúnebre de enontes, vuelven los cuchicheos $\mathrm{y}$ el rumor.

¡Qué agitación por la pequeña sala! ¡Cómo insuflando el pelctón se apiña! ¡Cuál su fragancia cada flor exhala! ¡Cuál su púrpura el rostro de la niña!

$Y$ en ella dormita aún $\mathbf{i} \ldots$ ! $Y$ tan bien duerme, que cuando la saluda el sol que nace, la encuentra inmóvil en el lecho... inerme! ¡La adorada beldad cadáver yace!

Ya junto a sus hermanas no palpita; y cunque están sonrosados sus colores, ya ella también es otra flor marchita, ¡Muerta por la fragancia de las flores!

(Versión de Juan de Arona, inserta en "Los Románticos", Tomo 8 de la Biblioteca de la Cultura Peruana, por V. García Calderón, Pa-

Biblioters, Desclee de , Brourer (9938).

\section{"Jorge Puccinelli Converso»}

A D D A

(De Ludwig Klein)

Ríe y son las notas de su risa armónicas, alegres y sonoras, como si un collar de perlas se contara $y$ cayera en el fondo de una copa de pulido cristal donde saltaran.

Habla, y sus palabras al oído acarician cual sílabas de un verso; parece que el rubí vibrara de su labio, desenvolviendo el eco 
de una música angélica y lejana llena de cadencia y de misterios.

Los más dulces recuerdos de la vida su voz hace volver a la memoria; y allá del incensario de su alma su casto y puro pensamiento brota $y$ se eleva llevando sus aromas hasta el alma que, muda y abstraída, la contemplara absorta!

Mira, y la casta luz de su pupila dulzura y paz en derredor derrama; quedan mudas las mismas pasiones: $y$ al buscarse palabras que del alma traduzcan la profunda adoración, encuéntrase tan solo por lenguaje el turbado latir del corazón.....

(Versión anónima publicada en "El Perú Ilus. trado", Lima, 5 de octubre de I889).

\section{AL P P E T A D E L A M O R}

(De Federico Riickert 1788-1866)

Labra ¡oh poeta! tus estrofas bellas en el duro granito del dolor, y más provecho alcanzarás con ellas que si cantas la dicha y el amor.

Que el hombre se abandona, agradecido, al que logra su enigma adivinar; $y$ muchos el placer no han conocido, mas ninguno ha dejado de llorar.

(Versión de Juan Tassara, probablemente de lia traducción francesa, publicada en "Balnearios". Barranco, 14 de diciembre de 1913, No 166). 


\section{B A L A D A}

(Federico Riickert)

Puede más que la codicia

En el hombre la ambición

De un árabe esta noticia

Refiere antigua canción.

Hassan, le dijo un amigo,

La yegua á robarte van.

Antes lleve mi enemigo

A mi mujer, dijo Hassan.

Invencible en la carrera

rauda como el aquilón,

Cifra en su yegua ligera

El árabe su ambición.

Y á la cama de su tienda, para más seguridad,

Aquella noche á su prenda

Encadena su ansiedad.

Pero estando Hassan dormido,

El dadrón lse desilizó

Junto á su lecho y $\sin$ ruido

Soltó la yegua y montó.

Alerta, grita, en buena hora

Logré tu yegua robar

Prueba Hassan tú mismo ahora

$\mathrm{Si}$ se la puede alcanzar.

Hassan a sus deudos llama

Y al ladrón siguiendo van

Como persigue á la llama

El soplo del huracán.

Diéronle caza sin tregua

$Y$ al irla ansioso á coger

Se acuerda Hassan que la yegua

Iba su fama á perder. 
Si te alcanzo, se decía, Vencida al fin quedarás; Si te dejo, yegua mía, Ya de otro dueño serás.

Mas huye, corre ligera, Que te roben veces diez Prefiero á que en la carrera $\mathrm{Te}$ alcancen una sola vez.

$Y$ de una treta se acuerda Para hacerla desbocar: Pícala la oreja izquierda, De pronto empieza á gritar.

Que en tol parte la picaba Cuando, ocosada tal vez A desplegar la excitaba $\mathrm{Su}$ indómita rapidez.

No en vano Hassan aconseja En daño propio al ladrón;

Pronto atrás á todos deja, Raudo como el Âquilón. IaS

Tu yegua al ladrón regalas, Mírale ya donde va Si tú mismo das alas, ¿Quién alcanzarle podrá?

La tribu así le critica; $Y$ él con profundo dolor, La he regalado, replica, Pero he salvado su honor.

Me servirá de consuelo Saber que robada fué, No vencida en raudo vuelo $\mathrm{Ni}$ yo mismo la alcancé.

(Versión anónima, publicada en "La Tribuna", Lima, 6 de mayo de 1879, No 178, año II). 
POETAS MODERNOS

\title{
EL ANGEL DE LA GUARDA
}

\author{
(D. DAS BLCH DER BILDER, por Rainer \\ María Rilke 1875-1926).
}

Eres el pájaro cuyos vuelos vienen

en la noche cuando me despierto y llamo.

Llegas al solo grito de mis brazos, pues tu nombre se pierde en abismo oscuro de mil noches.

Eres la sombra en que duermo tranquilo.

Tu fuente y raíz vislumbro en mis sueños.

Tú eres la imagen y yo el marco

de luminoso relieve que te circunda.

¿Cómo he de nombrarte? Mira mis labios entumecidos.

Tú eres el introito que se difunde pródigo,

yo soy el tímido y lento amén

concluyendo enajenado tu belleza.

Me has arrancado a menudo de la oscura inercia, cuando el sueño me parecía como lá lumba

y como el caminar perdido y la huída.

Entonces me sacaste de la lobreguez del corazón

$y$ quisiste izarme en cada torre

como las galanuras de los tomeos y las banderas escarlatas

Tú que hablas de milagro y de sabiduría,

como de los hombres y de las melodías y las rosas,

de acontecimientos que relumbran y desfilan en tu mirada;

Tú, bienaventurado :

¡Cuándo le nombras una vez siquiera,

a EL de cuyo séptimo y último día

aún hay fulgores en el temblor de tus alas perdidos!

¿Consientes en mi ruego?

(Primera versión inédita de Carlos Augusto Pásara). 


\section{EL ANGEL DE LA GUARDA}

Ala que venías, ave de mi noctumo despertar clamando.

Tan sólo mis brazos gritaban, pues tu nombre, cual abismo, es en mil noches profundo.

Sombra que me dormías en la calma, brotan mis sueños de tu semilla.

Eres la imagen, mas soy el fondo

$y$ tu relieve de luz lo complemento.

¿Cómo he de nombrarte? Mira mis débiles labios.

$\mathrm{El}$ introito eres que se difunde pródigo, yo el angustiado y lento amén. con temor tu belleza concluyendo.

A menudo me arrancabas de la oscura inercia, cuando el sueño presentábase como la tumba como el eviadirse

Y perderse.

De las tinieblas del corazón me recogías entonces, $y$ en cada torre deseabas enarbolarme como galanuras y pendones escarlata.

Tú, bienaventurado, que hablas del hombre y la sabiduría, del milagro, las melodías y la rosa -y ocurren y llamean los acontecimientos en tu mirada-: ¡Cuóndo ya le nombras, cuómdo, a EL, de cuyo séptimo y último día aún queda fulgor perdido sobre tus alas batientes! ¿Ordenas que yo pregunte?

(Segunda versión inédita de Carlos Augusto Pásara). 


\section{EN NOCHE DE TEMPESTAD \\ (Cuatro Hojas y Una Portada) \\ De "Das Buch der Bilder", por Rainer María Rilke.}

\section{CUARTA HOJA}

Son las noches como ésta que allí en los sarcófagos rompen a caminar - lo mismo que antañolos corazones de los antiguos príncipes. ¡Cuán poderosos golpean los latidos en cada estuche alongado y resistente! Persiguen a las ánforas doradas, que mueren por tinieblas $y$ damascos. ¡Oh negra catedral y remecida, el vario sonido, las trémulas puertas!

Como pájaros, las campanas, que no doblan, se prenden y columpian en las torres. $\mathrm{Y}$ se agitan los cuerpos de los pilares, cual sostenido el cimiento berroqueño por ciegas fortugas en vaivenes.

"Jorge PucqiTraduccióngnédialde Carlos Augusto Pásara).

\section{AL ROCE DE VIENTO DE MUERTE}

\section{Hans Carossa}

Sobre los membrillos, de un amarillo limón,

Cae en murmullo una nieve temprana.

El niño pregunta por su trineo,

Pero mirad, abajo, hacia el lago :

Delante de humeantes fuegos

A medio apagar, están los soldados.

Una campesina se asoma por la granja

$\mathrm{Y}$ se lleva al oído la mano. 
Ni cerca ni lejos, con sonido hueco,

Caen lentos golpe sobre golpe,

Perdidos casi entre los copos que caen;

Sin embargo, animan el día.

$Y$ retiñe la ventana y tiembla la pared¿Sentís, ahora, dónde estamos?

Oh, cómo adquiere nuevo vigor la vida Al roce del viento de muerte.

Se iluminan todas las horas fuertes

Del ser nunca asible

Con goce santo y heridas santas-

Amigos, a nosotros compete sólo

Seguir construyendo despiertos

Lo que empezamos en sueños.

El empeño es grande, no hay horror

Bastante para nuestro ánimo.

Cojamos los lirios del espíritu

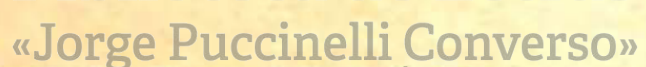

Muy arriba en el precipicio,

$Y$ ataviemos nuestra mesa

Aunque perecer tengamos.

En la mano de hermosura juvenil

Luce un racimo sobre hoja amarilla,

El otoño ha dejado un reborde verde

En la enramada descolorida.

(Versión de Emilio Adolfo Westphalen y Enrique Solari Swayne, publicada en "Las Moradas", Nos. 7-8, Lima, enero-julio 1949). 


\section{DES PEDID $\bar{A}$}

עe Oscar LOERKE

Seguirá creciendo el aceite, seguirá ascendiendo la resina, la montaña de fuego nadará sobre nubes, en el mar universal;

la nueva nube de pinos, como sombras de Vulcano, trepará las cuestas con suavizada gravedad.

Deseas estar muerto, corazón, sólo cual perfume de naranjas puede un dios traer aquí tus flores, sólo una roja bola, entre los cientos de árboles, desea tocar aquí, nuevamente, a las arenas benditas.

(V.ersión de Víctor LI Carrillo publicada en "El Comercio" de Lima, Suplemento, I\$ de enero de 1956).

\section{Biblioteca de Letras}

